\title{
J
}

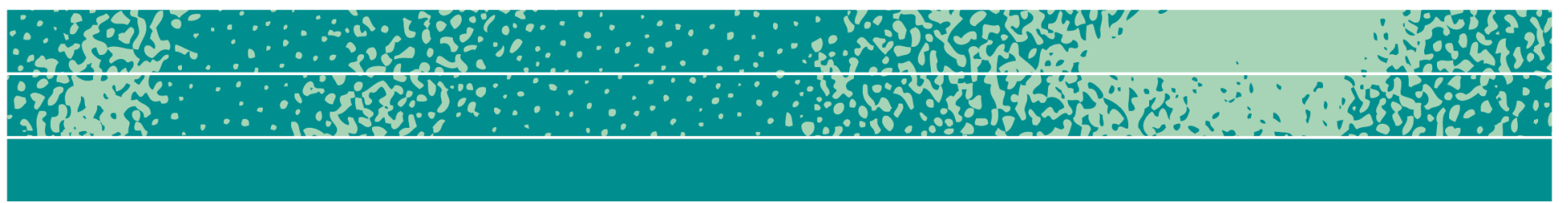

\section{Global Business Anthropology Summit 2018: Summary and Reflections}

\author{
Allen W. Batteau
}

On April 24, 2018, 74 business anthropologists and students from nine

Page 1 of 10 countries met at Wayne State University in Detroit to discuss the current state and future directions of business anthropology. This specialtywhich has experienced substantial growth over the past ten years, with two new journals, an industry conference, and a major initiative at the annual meetings of the American Anthropological Association in 2017-is marked by both theoretical and practical challenges and significant opportunities.

Business anthropology has emerged to respond to a growing need, in corporate and government bodies, for a close examination of the behavioral and cognitive influencers in decision making. The applications have grown with every passing year, from advertising to marketing to product development to governance to mergers and acquisitions to banking, and well beyond. Preparation for careers in these fields is not more than 25 years old, but the demand is growing exponentially. A core purpose of the Business Anthropology Summit has been to frame the agenda for this relatively new discipline, thus making it easier to learn and collaborate within our community, and to initiate new corporate and government collaborations and projects that reflect anthropological perspectives and methods.
JBA 8(2): 298-307

Autumn 2019

(C) The Author(s) 2019 ISSN 2245-4217

www.cbs.dk/jba 
The Summit was preceded by the submission of issues statements by the participants, the content analysis of which revealed three overriding themes:

- Practicalities of the work

- Market trends

- Training the next generation of academics and practitioners

An opening plenary featured presentations on each of these three themes by Rita Denny, Robert Morais, and Christina Wasson. After a general discussion, six working groups, randomly composed of all the Summit participants, discussed each of the three themes. The most prominent proposals raised by the working groups can be summarized as follows:

- Improved communication with both academic colleagues and business coworkers and clients. We are prepared to work with our colleagues in the academy and in business to strengthen communication channels.

- Substantial changes are needed with regard to how graduate departments train their students in the anthropology of and for business, particularly when students are headed for careers outside anthropology departments. We are prepared to work with training programs on productive enhancements.

- More interchange between academics and practitioners is needed. We need to enrich the forums available for interactions among anthropologists affiliated with academic and business organizations.

- Reaching out to the general public, in terms of promoting Business Anthropology. Increasing the public visibility of the contributions anthropologists make to productive, socially responsible business enterprises.

The beginnings of what is known today as "business anthropology" may be found in an early study by W. Lloyd Warner and J. 0. Low, The Social System of a Modern Factory (Warner and Low 1947). In the 1930s, Warner, whose initial fieldwork was among the Murngin of northern Australia, turned the ethnographic gaze toward modern communities and institutions with his five-volume Yankee City series. Ever since, the anthropological study of contemporary institutions and communities has coexisted, albeit uneasily, with anthropology's dominant focus on the unfamiliar and the exotic. For better or worse, this abilityto familiarize the exotic and, conversely, to exoticize the familiar-is anthropology's calling card.

In the 1980s, a focus on corporate culture reinvigorated anthropological interest in contemporary business, and in 1983, the first 
course in "Business Anthropology" was launched at Wayne State University. During the mid-1980s, marketers began incorporating anthropological methods and theory into their work, and that application, along with the use of anthropology in and for design, has gained substantial traction over the past several decades. At the end of the 20th century, the tech boom-which delivered not simply new devices but also new experiences, new social and civic spaces, and new ways of seeing the world-led to a growth in employment of anthropologists in hardware and software industries and an appreciation of the ethnographic methods of immersive comprehension. In 2005, two of the firms leading this boom, Microsoft and Intel, launched the Ethnographic Praxis in Industry Conference (EPIC), which marked the coming of age of ethnography in industry. An ongoing debate marks the distinction between "anthropology" and "ethnography" and the standards and boundaries of each; nevertheless, anthropology and anthropological methods are recognized as having a useful and important contribution in many corners and functions of the business world, including design, product development, marketing, organizational development, and change management.

In this history, there is the familiar trajectory of scientific innovation moving from universities and laboratories into government and industry - and ultimately making important contributions to the productivity and effectiveness of both. Contemporaneously, the business press began taking notice of anthropology, and anthropological studies of specific products and brands began having an impact in business.

Growth, of course, creates challenges, and some questions arose alongside the increasing significance of business anthropology:

- Can anyone call him- or herself an anthropologist? Should there be a form of credentialing?

- Do the ethical guidelines of academic research apply to the use of anthropology in industry? Are distinct ethical guidelines needed for Business Anthropology?

- What responsibility does business anthropology have to contribute to the greater social and economic good beyond project parameters?

- How should the familiar ethnographic techniques of prolonged immersion be adjusted for the fast-paced demands of contemporary industries?

- What adjustments are needed within academic training programs to prepare anthropologists for these new opportunities? 


\section{ISSUES AND AGENDA}

In her opening remarks on the practicalities of the work, Rita Denny made several key points, the first of which was the need to fit in to the organization(s) where we want to work. Thus, knowledge of the relevant languages and processes ahead of time is helpful. Her second point, however, was that it is not enough to fit in; in order to steer change, we must both fit in and have an alternate vision of the endeavor. We must be a subtle combination of a member of the organization and an anthropological change agent. Organizations should be treated as field sites, with all of the open-mindedness, attention to language and processes, and curiosity that implies. Labels are power: how we identify ourselves affects how we make markets for ourselves. Labels, however, can be empty and hollow if they are limited to the discourses of business. Business anthropology is more than a research method, and ideally, business anthropologists are many things, from artists and designers and engineers to CEOs. To take on this role, practitioners will need to be creative, ambitious, theoretically adept, and acute observers of and for the work they produce.

In his discussion of market trends, Bob Morais suggested three jumping off points for the Summit breakout sessions:

(1) responding to the increasing veneration of data science, especially artificial intelligence; (2) doing more to predict cultural trends that impact business; and (3) furthering our role as zeitgeist gurus. Data science promises more expansive and projectable findings and, for some, greater insights than are obtained through qualitative research. This potential poses an existential threat to qualitative approaches, but also suggests a major opportunity for business anthropologists: we can collaborate with data scientists, together producing high-level analytics and deep analysis. Tricia Wang similarly addresses this idea in her TED Talk, "The Human Insights Missing from Big Data"; we can take her argument further by partnering more intimately with data scientists, not only serving as the ethnographer in the room but helping data scientists to formulate more penetrating questions, conduct closer virtual observations, and incorporate anthropological theory to ignite richer insight generation. Regarding cultural trends, businesses need to anticipate change, and they must have confidence in their forecasts. This point offers anthropologists an opportunity: those involved in technology must work to anticipate change, while those working in marketing and organizational culture-who too often focus more on what is than on what is to come-should find ways to identify cultural change that executives don't see coming.

The third set of opening remarks was from Christina Wasson, discussing training the next generation of business anthropologists. She began with the observation that business anthropologists have been concerned about this issue for many 
years. Most did not receive preparation for applied careers in their graduate programs and have seen traditional anthropology graduates fail in the business world because of their lack of preparation. While some anthropology programs provide training in business anthropology, most do not. Wasson suggested that the summit offered an opportunity to envision what the ideal training for future business anthropologists might look like and to develop ideas on how to translate that vision into practice. She suggested keeping in mind three dimensions during Summit discussions. One dimension was the different training contexts: anthropology departments, design schools, or business schools. A second dimension was that each training context can be placed along a continuum of training depth, from a minor focus on business anthropology - perhaps a single course taught by an adjunct-to a strong focus with dedicated faculty. A third dimension was types of students and their needs. At the University of North Texas (UNT), students tend to cluster into two groups: young students who often have a strong anthropology background but need to learn the cultural logic and practices of working in a business environment, versus established professionals who may be new to anthropology and need to learn our theories and methods and how apply them in fields like design or marketing. Wasson concluded with five learnings from UNT: First, it is valuable to situate business anthropology within applied anthropology. Second, anthropology should be integrated with training in other relevant fields, such as design or marketing. Third, the integration of theory and practice is essential. Fourth, students should be given many applied project experiences through class projects and an applied thesis. And finally, it is helpful to include a class focused on professional skills and thesis client development.

Several issues were raised in the ensuing discussion:

Communicating value a very broad theme. When we talk about communication, it is more than just having conversations; in order for business anthropology to grow, communication needs to be focused and intentional. Our communication needs to play to our strengths and value and engage with a wider audience than academic anthropology. The teams identified three important topics.

First, communicating the value of anthropology in business is extremely important, which suggests the usefulness of a mass media presence. To continue the growth that we have seen so far, our value must be understood by organizations, which means anthropology must make a big push to promote its value in a business setting. If anthropology is just seen as a niche market, then growth will be harder to come by. The biggest question is: how do we enter mainstream business and make anthropology indispensable to companies? This is not an easy task, particularly given the tendency of most anthropology departments to keep out of the public sphere, at least in the United States. Other 
anthropology departments across the world can give us a good idea of how to communicate our value. In business-government-NGO career paths, the main emphasis is in training aspirants to focus on how they can contribute to the organization's success. This focus marks a big shift in thinking-away from the individual and toward the organization.

Second, insights are important, but they are not often fully understood. This point is especially true in anthropology, where insights gained are rarely translated into actionable items. If business anthropology is to thrive, then anthropologists must get better at communicating. Many currently in the field are well practiced at translating insights, but for new anthropologists and students, this process can feel unnatural. Changes will come as students learn more about the needs of businesses and how to turn insights into action. As more anthropologists are employed by companies, their insights will be more valued as they prove effective.

Business anthropology is positioned in a liminal area, which allows us to see multiple perspectives, and part of our strength comes from the unique perspectives that we are able to provide through insight. "Liminality is our trade and we can build consensus by communicating other views" - that is, viewpoints from the edges. This is one of anthropology's great strengths, but we have to be effective in communicating these views. When we are able to communicate multiple or synthesized perspectives, we provide invaluable resources to companies.

Finally, an important part of communicating value is public engagement. Anthropology has often been misunderstood, due in part to its lack of outreach, though this has been changing as more anthropology is localized. In business anthropology, engagement is a must, since business anthropologists often become the voices of the consumers, making sure their needs are met. There is still a long way to go, but there are examples of how we can engage effectively (University of Copenhagen). In Europe, public engagement is an expected part of academia, and academia demonstrates its value more easily.

Nearly every group agreed upon the use of case studies to promote business anthropology to the business community. There are many case studies in circulation already but they are not always well known. There have been several articles published in popular business press about anthropology, but these could be seen as a novelty. In order to show our consistent value as anthropologists, we must demonstrate what we provide. Anthropologists can use case studies to expand into the business world and demonstrate their value and capacity for creating more opportunities.

However, not all case studies are created equal, and one participant brought up the danger of relying too heavily on case studies to 
present our message: "Problems of case studies: if it is too brief and not enough depth anyone feels like they can do it. They are 'ethnographers'; if it is too complex it costs too much money and the meaning gets lost." Thus, we have to be very intentional about what we send out. How do we want to communicate our value? If a case study can do that, then send it out, but we must be aware of the risks.

Ethics and Standards of Responsible Professional Conduct are a major concern to anyone associated with business anthropology and was a major topic for the Summit participants. In academia, the Institutional Review Board (IRB) is designed to protect the interests of participants in a study. In business, there is not a standard ethical code, so business anthropologists must work one out themselves. With recent events (e.g., Facebook and Cambridge Analytica), more thought needs to be given to ethics.

"We are at a critical juncture with the rise of technology giants in society: challenges such as privacy for consumers and their protection with safety. What is right and what is wrong for individuals, groups and the population. If we are to wrestle with these subjects in a corporate domain, they become complex answers. We used to have a robust ethical code. Now it is suited but ambiguous."

At this point, it seems the AAA code of ethics plays very little role in business. Thus, the ethics of anthropologists working in business must be internal. They must hold themselves to a higher standard and advocate for a higher ethical standard in their company.

Many good ideas came out of Summit discussions. The ideas may vary based on the industry an anthropologist works in, but this provides a good starting point:

- challenges such as privacy for consumers, opening risks of autonomous vehicles; bringing about issues of what's right/wrong for various groups and populations

- corporate context: understand the domains in which technology engages

- looping back with participants at multiple stages of the design process

- let participants know what happened to the product

Ethical problems can never be fully resolved. Right now, we can make sure that we are holding ourselves to the highest standards and ensure that we are properly training the next generation of anthropologists.

A third issue is relationship-building. Any good anthropologist can quickly build and maintain relationships. There are two areas where 
business anthropologists must build stronger relationships: with each other and with private and public sector organizations. First, relationship building is important within the business anthropology community. There needs to be a stronger community of business anthropologists, which events like the Summit and awareness at the American Anthropological Association (AAA) annual meeting are designed to address. This Summit and other efforts have served as good starting points, but there is much still to be done.

It is also important to build relationships in the internal anthropological community with other anthropologists at our universities. In the most traditional anthropology departments, business anthropology is not looked on favorably-though this is beginning to change. Nevertheless, there seems to be a sense among traditional anthropologists that business anthropology has sold out for the lure of money and other capitalistic gains. It is thus important to the success of business anthropology to educate and inform other anthropologists about the benefits of business anthropology.

The American Anthropological Association has a keen interest in seeing the success of business anthropology and wants events like this summit to succeed. Ed Liebow, the executive director of the AAA offered some insight: Six years into his role, he sees the principal agencies of change as the academic departments of anthropology; they are the sites of intervention, and it's important to nudge them. There are resources and support to aid in educating departments, but business anthropologists will need to take the initiative in engaging their coworkers.

Second, with regard to external organizations and constituencies, if we look at business, engineering, and medical schools, we see a vast network of contacts, funding, and internships that can prepare students for work in their respective fields. These networks are more difficult to come by in anthropology, but they are also becoming more important. Students are not receiving the training that they need to be successful in a business setting, but by partnering with outside organizations, we can increase training opportunities, draw others to the field of anthropology, and allow the field to grow.

As companies gain more exposure to anthropology, they will become more comfortable with our methods and analysis. Hiding our thought processes and theories should become a thing of the past, even if it's tricky to make that happen. We must teach all anthropologists and anthropology students how to build relationships and sell our skills.

There was a lot of discussion about how to train new business anthropologists and what they need in order to be successful, and there was no shortage of ideas. The overwhelming conclusion was that we need to train anthropologists differently; anthropologists need to be multifaceted and steeped in multidisciplinary methods. For some areas of 
business anthropology, that is a natural approach (design anthropology), but for others, greater adaptation and interpretation is required. Indeed, the difficulty with training is that it often needs to be very specific. A design anthropologist will require different skills than one who does marketing. Business anthropologists first need to understand business terms, research methods, and other entrepreneurial skills. Most departments are not equipped to teach these skills, so building connections with business schools can allow students to get the training they need. At present, some students have found it necessary to combine an anthropology degree with another degree, whether in design, business, or engineering. Suggested skills include:

- theory and methods-qualitative

- quantitative comfort

- business training

- design

- AGILE (Design Research) is contemporary ethnography (working in short periods/quick research, then ideate)

- soft skills-empathy, understanding, human-centered design

- maintain one's identity as an anthropologist of some kind

- multiple levels of expertise $\longrightarrow$ deepest in one area

- communication

- collaboration

- digital literacy

- intellectual self-confidence

- quantitative literacy

Anthropology departments teach some of these skills well, but there are others that departments are not equipped to teach. That is where outside relationships are important: by bringing in practitioners who have the needed expertise, anthropology departments can teach the students the skills they need. Departments can also create relationships with other departments, since having students take classes outside of anthropology will also facilitate multidisciplinary training.

The energy and enthusiasm of the 2018 Global Business Anthropology Summit far exceeded the expectations of the organizers and sponsors. As a consequence, a second Summit was organized at Fordham University on May 29-30, 2019, and plans are underway for the 2020 Summit in Berlin and the 2021 Summit at Universidad Iberoamericana in Mexico City. This global reach makes it clear that Business Anthropology is firmly established on the global stage. 
Equally important is the identity and reputation of Business Anthropology. A parallel effort is underway to define the brand identity of Business Anthropology, both in terms of its tangible value and what it adds to a business. There is an initiative underway to create a brand for Business Anthropology that would have resonance in both the business and professional worlds, making the value of Business Anthropology both clear and appealing. These matters will be discussed over the year leading up to the Berlin Summit.

We would like to thank the following companies and institutions for their support for the 2018 Global Business Anthropology Summit:

Hitachi

$\operatorname{ReD}$

Fjord

Wayne State University

Nissan

Intel

Allen W. Batteau is Professor of Anthropology at Wayne State University in Detroit, Michigan. He can be reached at: a.batteau@wayne.edu. 